\title{
revivista educação
}

DOI: 10.33947/1980-6469-v14n1-3295

\section{AVALIANDO O PIBID ENQUANTO POLÍTICA PÚBLICA DE INCENTIVO E VALORIZAÇÃO DA DOCÊNCIA}

\section{EVALUATING THE PIBID AS A PUBLIC POLICY OF ENCOURAGING AND VALUING TEACHING}

\section{RESUMO}

\author{
Erinaldo Ferreira Carmo¹, Carlos Alberto Vasconcelos ${ }^{2}$
}

Este artigo apresenta, de forma descritiva e analítica, os resultados de um relato de experiência e de uma pesquisa sobre o olhar de diferentes agentes pedagógicos acerca da política de bolsas de iniciação à docência instituída pela Capes. Aqui são observadas questões inerentes à formação profissional para a docência, à realidade das licenciaturas e às ações transformadoras dos estudantes e professores participantes do Pibid. Os resultados indicam que a inserção dos estudantes universitários na vivência escolar produz efeitos positivos sobre a identificação do discente com o seu curso, a valorização da profissão docente e o apontamento de ações viáveis à educação básica nas escolas públicas contempladas pela referida política de formação e aperfeiçoamento de pessoal docente.

PALAVRAS-CHAVE: Pibid. Políticas públicas em educação. Formação docente. Residência pedagógica.

\section{ABSTRACT}

This article presents, in a descriptive and analytical way, the results of a research on the perspective of different pedagogical agents on the scholarship policy initiated by Capes. Here we observe issues inherent in professional training for teaching, the reality of degrees and the transformative actions of students and teachers participating in the Pibid. The results indicate that the insertion of university students in the school experience has positive effects on the identification of the student with his course, the valorization of the teaching profession and the indication of viable actions to basic education in the public schools contemplated by said policy of formation and improvement of teaching staff. KEYWORDS: Pibid. Public policies of education. Teachers' education. Pedagogical residence.

\footnotetext{
1 Doutor em Ciência Política. Coordenador do Mestrado em Políticas Públicas da UFPE.

2 Doutor em Geografia. Pós doutor em Educação Contemporânea. Departamento de Educação Universidade Federal de Sergipe.
} 


\section{Introdução}

O Programa Institucional de Bolsa de Iniciação à Docência (Pibid) surgiu com a criação da Diretoria de Educação Básica Presencial (DEB) ${ }^{3}$ pela Lei $n^{0} 11.502$, de 11 de julho de 2007, que conferiu à Coordenação de Aperfeiçoamento de Pessoal de Nível Superior (Capes) competências para fomentar a formação docente e estimular a valorização do magistério em todos os níveis e modalidades de ensino. Essa medida, de imediato, alterou a função original da Capes que, historicamente, e até então, tinha o papel central de promover, regular e avaliar os cursos e programas de pós-graduação stricto sensu, assumindo, a partir desse momento, mais uma linha de atuação, agora voltada para a indução e o fomento da formação inicial e continuada de professores para a educação básica.

No início, o Pibid foi planejado tendo como prioridade o atendimento às licenciaturas em Física, Química, Biologia e Matemática, dada a carência de professores dessas disciplinas no ensino médio. Entretanto, durante a implementação do programa, a área de abrangência foi amplamente alargada, passando a atender todas as disciplinas de formação que contemplam a educação básica.

Embora o programa tenha surgido em 2007, as atividades referentes à distribuição de bolsas só tiveram início no ano de 2009, quando foram contemplados 3.088 bolsistas, de 43 instituições de ensino superior. Em 2012, esse número já tinha saltado para 49.321 bolsas, sendo 40.092 estudantes licenciandos, 3.052 professores coordenadores e 6.177 professores supervisores. E em 2014 o programa atingiu o seu maior número de bolsas, 90.254 , contemplando 2.997 subprojetos em 855 campi de 284 instituições de ensino superior, abrangendo cerca de 5.000 escolas da educação básica. A partir de então, o Pibid sofreu cortes e frequentes ameaças de redução drástica das bolsas e até mesmo de extinção do programa, acompanhando a crise política e econômica instalada no país.

Mesmo com o corte de verbas e as incertezas de continuidade do programa, presentes entre os bolsistas nos últimos anos, em 2017 foram ofertadas, em

\footnotetext{
${ }^{3}$ O Decreto $n^{\circ} 7.692$, de 2 de março de 2012, alterou o nome dessa diretoria para Diretoria de Formação de Professores da Educação Básica, mas manteve a mesma sigla, DEB, por esta já estar consolidada na Capes e nas instituições de ensino.
}

média, 71.831 bolsas, considerando as quatro categorias de bolsistas (Iniciação à docência, Supervisão, Coordenação de área e Coordenação institucional). Pela sua grandeza e abrangência, e ainda que este seja um programa recente, com apenas dez anos desde a sua criação oficial, o Pibid se transformou em uma das mais relevantes propostas de incentivo à docência, representando uma significativa ação de política pública de formação e atualização de professores instituída na educação brasileira no âmbito de uma instituição fomentadora de aperfeiçoamento de pessoal em ensino superior, como a Capes, possibilitando aos bolsistas a dupla orientação simultânea, permitindo que esses sejam coorientados pelo docente da licenciatura (coordenador) e pelo docente da escola onde são realizadas as atividades práticas (supervisor). Desse modo, o Pibid se tornou uma grande estratégia de formação acadêmica e escolar, contemplando uma vasta quantidade de educandos e educadores nas universidades e nas escolas, beneficiando diretamente os estudantes das licenciaturas, em sua formação inicial, os estudantes da educação básica, com as novas ações de ensino desenvolvidas, os professores das escolas públicas, com a formação continuada, e os professores das licenciaturas, com o conhecimento prático da vivência escolar e a oportunidade de ampliação dos estudos, pesquisas e atividades de extensão voltadas para o ensino público na educação básica.

Dessa forma, é inquestionável a importância e grandeza do Pibid para a docência e inegável o seu poder de contribuição, em diferentes aspectos, no estabelecimento de uma nova dinâmica entre teoria e prática, universidade e escola, estudantes e professores, mobilizando recursos materiais e humanos para a questão da formação dos futuros professores e aperfeiçoamento dos professores já formados. Entretanto, como cabe aos estudos das políticas públicas, após o seu planejamento e a sua devida implementação e execução, faz-se necessária a realização das avaliações frequentes e aprofundadas para identificar se o programa caminha à contento do planejado, se há algum problema que possa ser detectado, quais as medidas que devem ser tomadas para solucioná-lo e quais as mudanças que são necessárias para a continuação ou a ampliação de sua abrangência e potencialidade. Essas medidas avaliativas, extremamente 
importantes nas revisões das políticas públicas em educação, devem ser constantes (efeito permanente) e sempre considerar as avaliações já realizadas (efeito cumulativo), compreendendo os objetivos do programa, os investimentos alocados e os resultados esperados e produzidos.

Foi nesse sentido que o presente estudo foi desenvolvido, com uma preocupação em apresentar uma visão geral do Pibid, com fulcro em avaliações anteriores, realizadas por distintos pesquisadores e publicadas em diferentes veículos de divulgação científica, abordando alguns resultados gerais ou pontuais de partícipes do programa, e ainda fazendo uso da observação participante e de entrevistas não estruturadas com bolsistas do programa, com o objetivo de contribuir com os estudos presentes e posteriores sobre a temática da formação docente. A observação se deu em duas escolas públicas na cidade do Recife e as entrevistas aconteceram em virtude da realização do Seminário Estadual do Pibid de Pernambuco, ocorrido nos dias 16 e 17 de novembro de 2017.

Após a conclusão desse trabalho, no início do ano de 2018, o Governo Federal lançou a Política Nacional de Formação de Professores, instituindo a Residência Pedagógica, com o objetivo de intervir na formação inicial dos licenciandos com o acompanhamento periódico dos professores em formação. ${ }^{4} \mathrm{O}$ Programa de Residência Pedagógica, à princípio, foi apresentado como uma ação do Ministério da Educação, coordenado pela Capes, no sentido de induzir o aperfeiçoamento do estágio curricular supervisionado nos cursos de licenciatura, promovendo a inserção do licenciando na escola de educação básica. Nesse aspecto, não se diferencia do Pibid e não representa uma melhoria da política anterior, inclusive pela restrição da adesão do aluno, que só poderá participar a partir da segunda metade do seu curso, enquanto no Pibid era possível ao licenciando aderir ao programa desde o início de sua formação.

\section{A formação profissional para a docência}

As pesquisas sobre formação de professores sempre estiveram presentes e com destaque nos

\footnotetext{
${ }^{4}$ Para visualizar o Programa, acessar http://www.capes.gov.br/ educacao-basica/programa-residencia-pedagogica
}

debates educacionais, ganhando novos argumentos recentemente por conta da inserção de mais um instrumento de mobilização que coloca conhecimentos teóricos e práticos em sintonia, antecipando aos licenciandos o convívio e a experiência escolar. Assim o Pibid foi imediatamente incorporado às pesquisas sobre a formação profissional de professores, ao mesmo tempo em que foi legitimado pelas comunidades acadêmica e escolar, tornando-se um elemento de apoio às disciplinas teóricas e complementar às disciplinas práticas, envolvendo os saberes inerentes à profissão e confrontando as referências conceituais diante da realidade vivida no chão da escola.

De acordo com Tardif (2000), os saberes profissionais dos professores são situados nos momentos vividos na prática da profissão. Isso significa que esses saberes, ainda que planejados e difundidos com base em teorias acadêmicas, são construídos e ganham sentido em função dos contextos de trabaIho nos quais são exercidos, isto é, adquirem sentido quando são concretizados em situações reais. Dessa maneira, o autor questiona o modelo comumente empregado de formação docente, como é praticado nas instituições de ensino superior, onde os cursos são desenvolvidos em uma estrutura de aulas que passa aos estudantes conhecimentos teóricos e logo em seguida estes são encaminhados para estagiar em escolas onde devem aplicar os conhecimentos adquiridos nas referidas aulas, tratando-se de um estágio organizado para a reprodução, em escala local, de um conhecimento geral e externo, e não exatamente para uma aprendizagem com a prática escolar, visto que, desse modo, o conhecimento é levado ao campo de estágio, e não desenvolvido nele, não permitindo assim o conhecimento prático das especificidades do ambiente escolar. Esse modelo é extremamente falho, como argumenta o mencionado autor, pelo fato da organização curricular da universidade ser baseada em uma lógica disciplinar, focada no conhecimento teórico e bastante distanciada do conhecimento da realidade das escolas e das práticas às quais estão inseridos os seus estudantes e professores, resultando numa dissociação entre o conhecer e o fazer na formação docente.

Nessa mesma linha, Saviani (2009) aponta para o vício da formação acadêmica, que confere um peso maior à formação geral e aos conteúdos disciplina- 
res, tornando secundária a formação pedagógica e o tratamento das questões da educação apropriada ao público onde ela se aplicará. Com isso, o autor concebe que a formação distanciada, preparatória para a docência, não encontrou, até hoje, um encaminhamento satisfatório e o que se revela permanente "é a precariedade das políticas formativas, cujas sucessivas mudanças não lograram estabelecer um padrão minimamente consistente de preparação docente para fazer face aos problemas enfrentados pela educação escolar" (SAVIANI, 2009, p. 148).

Essa é uma lacuna historicamente construída entre o saber acadêmico e o fazer profissional. Vasconcelos e Oliveira (2017) pontuam que ao longo da história, a formação de professores segue um modelo limitado, baseado em um padrão, como se a sala de aula e a realidade das escolas fossem homogêneas. Para eles, por décadas, o Estado forneceu um enquadramento normativo às instituições de ensino, submetendo professores e alunos às regras gerais padronizadas. Esse modelo não favoreceu a formação do profissional docente, por ser limitado à observação da prática, sem a completa imersão do formando no contexto da profissão. E como afirma Tardif (2000), para o profissional, o trabalho não é um objeto que se observa, e sim uma atividade que se exerce, e é nessa realização prática que os saberes são mobilizados e construídos. Numa interpretação dessa assertiva, aqui aplicada à atuação docente, entende-se que esses saberes se complementam. Isso significa que no aspecto profissional, a prática e os saberes não estão separados, mas sim entrepostos em uma situação real de trabalho onde se compõem (simbiose) e se transformam (metamorfose). Na educação, a simbiose e a metamorfose compõem a formação profissional. Mas só no universo formativo acadêmico a formação lida com a falta de articulação entre os estudos teóricos e a preparação para a prática docente, causando o distanciamento entre a realidade concreta das escolas e a concepção de ensino predominante nos cursos de formação de professores.

"Esse fato é provocado pela oferta de cursos de graduação e de pós-graduação acadêmica marcadamente teóricos, que pouco contribuem para a produção compartilhada de conhecimento, de maneira a impactar amplamente a sociedade" (SILVA, 2017, p. 729).
Por isso crescem os esforços para que o universo acadêmico se aproxime do mundo escolar, quando essa junção deve conduzir à construção de um repertório específico de conhecimentos voltados para o ensino, e as reformas devem definir padrões de competência à formação de professores e à prática do magistério, caminhando no sentido de que o ensino deixe de ser um ofício e passe a ser verdadeiramente uma profissão, semelhantemente às profissões de médico, engenheiro e advogado (TARDIF, 2000).

Essa pode ser uma importante variável a ser identificada como falha nos cursos de formação de professores: a separação entre academia e escola, ou seja, entre o campo de formação e o campo de atuação profissional. O primeiro se assume como a esfera onde se constrói o conhecimento, o espaço da pesquisa, o ambiente de planejamento, o campo definidor dos modelos de ensino; o segundo é representado como um mero local de aplicação, reprodução e execução do conhecimento pesquisado, planejado e definido na academia. Quanto maior esse pensamento separatista entre os que formam profissionais e os profissionais formados, maior também a distância entre o conhecimento apreendido e a execução prática da função exercida.

Tomando os profissionais da medicina e do direito, apenas como um exemplo, sabe-se que é comum a esses dois cursos a atuação simultânea de docentes na universidade e no exercício da profissão que ele forma: o professor que ministra a disciplina de prática em clínica cirúrgica também é o profissional que atua como médico cirurgião; e o professor que ministra a disciplina de prática forense também exerce a magistratura ou a advocacia. Mesmo não sendo regra, essa prática tornou-se referencial comum a esses acadêmicos e profissionais. O conhecimento do campo prático e a atuação profissional habilitam o professor a influir com maior propriedade na formação dos seus estudantes. Nas licenciaturas, a versão é oposta, apresentando apenas raros casos onde os professores das disciplinas práticas também são atuantes paralelamente na educação básica. O que ocorre na prática é a ação da desassociação entre o saber ser e o saber fazer, ou do ensinar sobre o desconhecido, referenciado apenas pelas leituras em produções teóricas, geralmente contextualizadas em outras realidades sociais. 
No âmbito acadêmico, os professores universitários que formam professores da educação básica também ensinam com suas próprias práticas, ou seja, suas ações são referências aos seus aprendizes (OLIVA et al, 2016). Por isso os estudantes consideram relevante nos seus professores as experiências prévias e as práticas atuais (SKAMP e MUELLER, 2001). Contudo, a ausência de referenciais práticos durante a formação pode fazer com que os licenciandos acabem reproduzindo as práticas de ensino assim como foram ensinados (CHENG et al, 2009). Por isso, alguns dos estudantes pesquisados nesse estudo citaram que aprenderam e reproduzem, ou tendem a reproduzir, algumas das práticas que perceberam em seus professores, mesmo aquelas que antes, quando eram estudantes da educação básica, não aprovavam.

Do conhecimento que se adquire primordialmente pelo exercício prático da função, o amplo conhecimento teórico auxiliará, mas não substituirá o empirismo na ausência deste. Nesse sentido, estudantes pesquisados destacaram que percebem e questionam essas lacunas em sua formação e registram que as oportunidades de inserção no campo profissional durante o curso são insuficientes para o enfrentamento dos desafios no exercício da docência (NASCIMENTO, 2016). As percepções dos estudantes reforçam as conclusões geralmente denunciadoras da formação dissociada do exercício da profissão que se estabeleceu nos cursos de formação de professores (AMORIM e VIEIRA, 2016).

Para agravar ainda mais a situação dos cursos de formação de professores, os estudantes relatam a situação desfavorável e de menor prestígio acadêmico e social dos cursos de licenciatura. E essa não é uma preocupação recente: estudos identificam que desde a década de 1960 a educação sofre a corrosão da profissão, mediante a deterioração salarial e o desprestígio social das experiências ligadas ao ofício docente (PAULILO, 2017). De outro lado, as políticas educacionais dos últimos anos atribuíram maiores responsabilidades aos professores, isso sem preocupações com a estrutura das escolas para a oferta de melhores condições apropriadas à realização do trabalho docente (COSTA e OLIVEIRA, 2011). Consequentemente, essa combinação fez com que a docência deixasse de ser atrativa para muitos jovens estudantes, que re- correram a outros cursos, sendo levados a escolher carreiras mais rentáveis ou de menor complexidade profissional.

A aprendizagem adquirida pela vivência, capacita e aprofunda o olhar do estudante quando este assume o papel de pesquisador participante, no momento em que observa e vivencia a escola, enquanto objeto de análise, e acompanha as práticas dos seus estudantes e professores, enquanto sujeitos que são o meio e o fim da educação, seres dotados de vida própria que não podem ser traduzidos unicamente em construtos teóricos. Essa é a humanização da educação, que ocorre pelo envolvimento e conhecimento dos seres humanos reais que a decompõem, filtrando as informações que recebem e selecionando as que se aproximam de sua realidade, e a recompõem, condensando os conteúdos que se relacionam com suas experiências de vida, convergindo assim para uma educação próxima a sua realidade vivida. Com efeito, como afirmam Saviani e Duarte (2010, p. 423) "se a educação é uma atividade específica dos seres humanos, se ela coincide com o processo de formação humana, isso significa que o educador digno desse nome deverá ser um profundo conhecedor do homem".

Reconhecendo esses problemas aqui descritos e respondendo às cobranças da sociedade por uma educação de qualidade, o Pibid foi pensado, então, como uma política pública de valorização e incentivo à docência, provocando mudanças paulatinas na percepção formativa dos agentes pedagógicos envolvidos (docentes e discentes dos cursos de formação de professores; docentes e discentes das escolas atendidas) e despertando um interesse maior desses agentes pelos estudos e pesquisas da formação para a docência. Em seu curto tempo de existência, desde a sua criação em 2007, relatórios apontam que já é possível reconhecer que os impactos iniciais do programa foram bastante significativos (CAPES, 2013; GATTI et al, 2014), mostrando que, entre as instituições envolvidas, foram percebidas: a aproximação entre universidades e escolas públicas da educação básica e a integração entre teoria e prática; a formação mais contextualizada e comprometida com o alcance de resultados educacionais; a melhoria no desempenho dos estudantes envolvidos no programa e a inserção de novas linguagens e tecnologias da informação e da 
comunicação na formação de professores; a participação crescente de bolsistas em eventos acadêmicos e em atividades de ensino, pesquisa e extensão; e o reconhecimento de um novo status para os cursos de licenciatura, produzindo uma elevação da autoestima dos licenciandos.

\section{O Pibid e a realidade das licenciaturas}

No contexto de ampliação e melhoria da formação docente, a Lei $n^{\circ} 13.005$, de 25 de junho de 2014, que estabelece o Plano Nacional de Educação (PNE), prevê, em sua meta 12, a elevação das taxas de matrícula na educação superior, mais especificamente entre a população de 18 a 24 anos. ${ }^{5} \mathrm{~A}$ preocupação da referida Lei em matricular um terço da população de 18 a 24 anos na educação superior ocorre por ser essa a faixa etária apropriada para esse nível de ensino, compreendendo o ingresso e a conclusão, para a partir daí entrar no mercado de trabalho com a qualificação elevada, no caso de não ter ocorrido a interrupção nos estudos regulares, e dessa população jovem, que compreendia 10.340 .513 pessoas, segundo a Pesquisa Nacional por Amostra de Domicílios (Pnad) de 2014, do Instituto Brasileiro de Geografia e Estatística (IBGE), somente $21 \%$ tiveram acesso ao ensino superior. Do total da população adulta, apenas $14 \%$ dos brasileiros chegaram ao ensino superior, apresentando o curso completo ou em andamento. Esse percentual é muito inferior ao registrado nos países da Organização para a Cooperação e Desenvolvimento Econômico (OCDE), cuja média é de $35 \%$.

Se a colocação da população jovem no ensino superior representa um desafio nacional, fazê-la cursar uma licenciatura se torna uma peleja ainda maior. Dos estudantes que cursaram ou estão cursando o ensino superior, de acordo com o Censo da Educação Superior (CES), realizado e divulgado pelo Instituto Nacional de Estudos e Pesquisas Educacionais Anísio Teixeira (Inep), a grande maioria das matrícu-

\footnotetext{
${ }^{5}$ O PNE, com vigência programada para dez anos (2014-2024), estabelece, na meta 12, a elevação da taxa bruta de matrícula na educação superior para $50 \%$ e a taxa líquida para $33 \%$ da população de 18 a 24 anos, assegurada a qualidade da oferta e expansão para, pelo menos, $40 \%$ das novas matrículas, no segmento público.
}

las está vinculada à formação de bacharel, como demonstra a tabela 1 .

Tabela 1. Matrículas no Ensino Superior (Graduação)

\begin{tabular}{clrr}
\hline Ano & Habilitação & Quantitativo & $(\%)$ \\
\hline 2011 & Bacharelado & 4.495 .831 & 66,9 \\
\cline { 2 - 4 } & Licenciatura & 1.356 .329 & 20,1 \\
\cline { 2 - 4 } 2013 & Tecnológico & 870.534 & 13,0 \\
\hline & Bacharelado & 4.931 .534 & 67,5 \\
\cline { 2 - 4 } & Licenciatura & 1.380 .829 & 18,9 \\
\cline { 2 - 4 } & Tecnológico & 993.612 & 13,6 \\
\hline & Bacharelado & 5.538 .834 & 69,0 \\
\cline { 2 - 4 } & Licenciatura & 1.471 .930 & 18,4 \\
\cline { 2 - 4 } & Tecnológico & 1.011 .439 & 12,6 \\
\hline
\end{tabular}

Fonte: Inep/CES.

Apesar do crescimento gradativo no número de matriculas no ensino superior, percebe-se que ele não se reflete de forma significativa nas licenciaturas. Isso ocorre, em parte, porque das milhares de vagas criadas com a expansão e interiorização das universidade federais, a maior parte foi destinada a cursos de bacharelado. Ao mesmo tempo, ocorreu o crescimento na oferta de vagas com o surgimento de novos cursos de licenciatura nas instituições privadas, que também ampliaram a oferta de cursos tecnológicos com formação em tempo reduzido, atraindo os estudantes que desejam uma formação mais rápida (CARMO et al, 2014).

Para se ter uma ideia dessa dinâmica, dos 1.471 .930 estudantes dos cursos de licenciatura no ano letivo de 2015, de acordo com o CES daquele ano, 39,3\% estavam matriculados em instituições públicas e $60,7 \%$ em instituições particulares. $61,6 \%$ desses licenciandos estudavam em cursos presenciais e $38,4 \%$ no ensino a distância, sendo $71,6 \%$ do sexo feminino e apenas $28,4 \%$ do sexo masculino. O CES 2015 revela, portanto, que os estudantes das licenciaturas, em sua grande maioria, são do sexo feminino, estão em instituições particulares e frequentam cursos presenciais no turno da noite. Esses estudantes encontravam-se distribuídos nos seguintes cursos, visualizados na tabela 2 . 
Tabela 2. Matrículas em Cursos de Formação de Professores (2015)

\begin{tabular}{lrl}
\hline Curso & Quantitativo & $(\%)$ \\
\hline Pedagogia & 648.998 & 44,1 \\
\hline Licenciatura em Letras & 168.201 & 11,4 \\
\hline Licenciatura em Educação Física & 149.011 & 10,1 \\
\hline Licenciatura em Biologia & 88.294 & 6,0 \\
\hline Licenciatura em História & 86.661 & 5,9 \\
\hline Licenciatura em Matemática & 84.522 & 5,7 \\
\hline Licenciatura em Geografia & 50.723 & 3,4 \\
\hline Licenciatura em Química & 35.892 & 2,4 \\
\hline Licenciatura em Artes & 29.199 & 2,0 \\
\hline Licenciatura em Física & 25.102 & 1,7 \\
\hline Licenciatura em Filosofia & 20.046 & 1,4 \\
\hline Licenciatura em Sociologia & 15.220 & 1,1 \\
\hline Licenciatura em Música & 14.855 & 1,0 \\
\hline Licenciatura em Ciências ${ }^{1}$ & 13.183 & 0,9 \\
\hline Licenciatura em Informática & 12.210 & 0,8 \\
\hline Séries Finais do Ensino Fundamental & 3.359 & 0,2 \\
\hline Outros & 26.454 & 1,8 \\
\hline
\end{tabular}

Fonte: Inep/CES.

Comumente, estudantes que frequentam cursos noturnos trabalham durante o dia, não dispondo de tempo para outras atividades acadêmicas diurnas. Essa é uma realidade nos cursos de formação de professores, fazendo com que os estudantes precisem atuar em seus estágios no mesmo horário de aula, o que pode retardar o tempo de conclusão do curso. E ainda que nesses cursos haja disciplinas práticas e atividades de estágio, o contato dos seus estudantes com a prática escolar sempre se torna reduzido, em detrimento da carga horária majoritária destinada à formação teórica e laboratorial. Por isso, o Pibid representa, aos estudantes contemplados por esse programa, um diferencial em seu processo formativo, inclusive pelo recebimento de uma bolsa que estimula a sua inserção direta no ambiente escolar, de modo mais aprofundado e duradouro.

Cabe aqui destacar que muitos alunos pibidianos entraram no programa desde o início do seu curso de licenciatura. Isso, de certa forma, estabeleceu um forte vínculo, não só com o programa, mas também com os proventos que dele recebem, tendo em vista que alguns estudantes são de baixa renda e apontam uma dependência maior das bolsas como auxílio à permanência no curso.

Nesse aspecto, o Pibid fortaleceu as licenciaturas por colocar os formandos em contato direto com sua profissão de formação, e ainda se diferenciou do estágio supervisionado por fornecer um incentivo financeiro, além de uma proposta extracurricular, com carga horária maior, e do acolhimento de bolsistas desde o início do curso. Outro fator positivo atribuído ao Pibid é a inserção direta no cotidiano das escolas, fato que ocorreu de forma orgânica e não apenas com caráter de observação. Dessa maneira, o programa assumiu como princípio a modificação das concepções dos sujeitos que estão implicados no processo: licenciandos, professores da educação básica e professores das licenciaturas, pois as atividades coletivamente planejadas e executadas valorizaram a participação conjunta desses agentes como protagonistas de sua própria formação. No Pibid, de acordo com o olhar dos agentes pesquisados, as relações entre os participantes do programa seguem vetores de influência (direta e indireta) que se retroalimentam, como mostra a figura 1.

Figura 1. Relações dos Agentes Pedagógicos

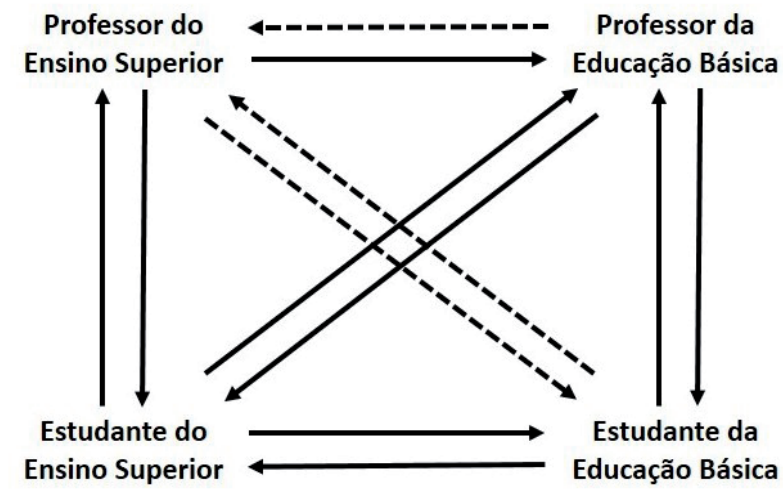

Elaboração dos autores, 2018.

Essa rede de influências ocorre por meio da reciprocidade nas relações e resulta no conhecimento global do complexo processo educacional e na utilização desse conhecimento na formação prática nos cursos de licenciatura. Com isso, começa a se propagar 
o fortalecimento desses cursos e a atração de novos estudantes, com a valorização da profissão. Assim, o Pibid se projeta na observação da meta 12 do PNE, voltada para a elevação da população jovem matriculada. Já na meta 15 , em sua estratégia 3 , o PNE, estabelece exatamente a ampliação do programa de iniciação à docência aos estudantes matriculados em cursos de licenciatura, a fim de aprimorar a formação de profissionais para a atuação no magistério da educação básica. No que diz respeito ao cumprimento dessa meta 15 , há o reconhecimento coletivo de que o Pibid foi significativamente ampliado desde a sua criação e até o exercício de 2014. Mas, por mais grandioso que pareça o quantitativo de bolsas disponibilizadas pelo programa, esse volume representa menos de $5 \%$ do número total de estudantes dos cursos de formação de professores. E tem crescido cada vez mais, mesmo entre os mais entusiasmados com o programa, uma preocupação alarmante com os cortes nos recursos alocados para essa política. A partir do ano de 2015, e até então, o Pibid passa por um processo de redução de bolsas e ameaças de cancelamento de alguns projetos, quando o quantitativo de estudantes e professores bolsistas começou a decair, como se vê no gráfico $1 .{ }^{6}$

Gráfico 1. Média de Bolsistas do Pibid

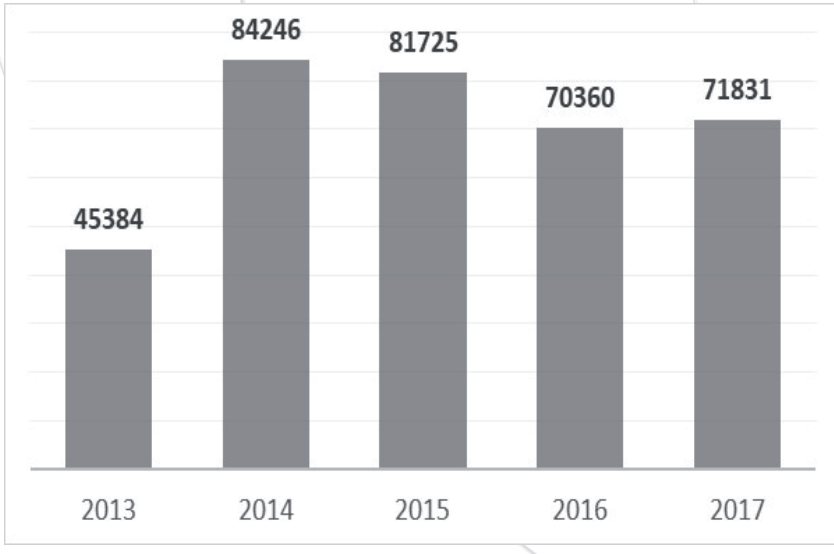

Fonte: Capes, 2017. Elaboração dos autores.

\footnotetext{
${ }^{6}$ Esse montante é sempre inferior ao total de bolsas anunciadas para cada ano. Há meses em que se distribuiu mais e meses em que se distribuiu menos bolsas. Por se tratar de uma média, esse valor compreende a quantidade de bolsas distribuídas ao longo de cada ano, considerando os dois semestres letivos.
}

O Pibid não é a única atuação da política da Capes voltada à educação básica, mas é, certamente, uma das mais relevantes medidas de apoio à formação docente, visto que abrange um expressivo número de pessoal e instituições e já começou a apresentar resultados positivos concretos. Além do Pibid, em atenção aos cursos de formação de professores e com o objetivo de incentivar e fortalecer a profissão, a Capes, por meio da DEB, criou projetos diversos e distintos voltados para a educação básica, mas eles pouco dialogam entre si e não produzem efeitos tão abrangentes e gerais, como é o caso do Observatório da Educação, com uma proposta de incentivo à articulação entre programas de pós-graduação e a educação básica; o programa Laboratório Interdisciplinar de Formação de Educadores (LIFE), para ofertar aos professores uma oportunidade de formação com o uso de novas tecnologias; o programa Novos Talentos, como incentivo ao desenvolvimento de atividades extracurriculares de aproximação entre cursos de graduação e de pós-graduação, com professores e estudantes da rede pública de educação básica; o Programa de Consolidação das Licenciaturas (Prodocência), de inovação no desenho de currículos e projetos pedagógicos de formação docente; o Programa de Desenvolvimento Profissional de Professores, como uma formação continuada aos docentes da educação básica; além dos Projetos Especiais de Apoio à Educação Básica, que ancoram ações de uso de instrumentos, metodologias e estratégias pedagógicas inovadoras, principalmente em regiões de baixo desempenho no Índice de Desenvolvimento da Educação Básica (IDEB).

Isso fez com que o Pibid tenha se tornado a mais abrangente política de formação da DEB. Em suas atividades de indução e fomento à formação docente para a educação básica, essa diretoria da Capes instituiu quatro linhas de ação: formação inicial; formação continuada e extensão; formação associada à pesquisa; e divulgação científica. Cabe aqui um destaque à medida adotada pela DEB de associar a pesquisa e a divulgação científica ao campo da formação inicial e continuada de pessoal docente, bem como o direcionamento de suas atuações à extensão, ultrapassando os muros da universidade. No primeiro caso, torna-se uma virtude atribuída ao Pibid a aproximação do ensino e da pesquisa, numa tentativa de 
corrigir a falha metodológica formativa instalada na universidade, de separar a formação para a pesquisa e a formação para o ensino, como se ambas as habilitações formativas fossem excludentes. A instituição dos cursos de bacharelado e das licenciaturas com disciplinas práticas distintas, forma os estudantes não apenas para funções diferentes, mas principalmente para atuações incompletas.

Essa separação, intrínseca à nossa formação universitária, limita e segrega o campo profissional dos formandos, pondo-os em campos opostos, sendo uns formados para pesquisar e outros para executar. Assim, essa separação força o licenciando, desde a sua formação acadêmica, a posicionar-se como replicador dos conhecimentos validados pelas pesquisas desenvolvidas por outros, como se os próprios professores não fossem capazes de pesquisar e trabalhar com os seus estudantes os recursos de suas próprias pesquisas e dos seus experimentos. Desde sempre, a universidade empenhou-se em sobrevalorizar o bacharelado, com uma formação voltada para a pesquisa e a continuidade nos cursos de pós-graduação, ao mesmo tempo em que reduziu acintosamente a importância da formação de professores para o ensino escolar, principalmente quando distribui os recursos em escala desproporcional e numa ordem classificatória, pondo a formação para a pesquisa, isto é, o bacharelado, em ordem superior à formação para a docência. Separar a formação tem sido uma falha que limita o conhecimento. Classificá-la, então, é um erro que o deforma.

A participação dos estudantes de licenciatura no Pibid e o seu envolvimento com a pesquisa no campo da educação fez crescer o interesse pela investigação e a busca por conhecimentos sobre os métodos de pesquisa, fazendo com que licenciandos também participem, em algumas instituições, de disciplinas de metodologia da pesquisa e concluam o curso de graduação com a apresentação de um Trabalho de Conclusão de Curso (TCC), modelo tradicionalmente cobrado aos bacharelandos. E entre os docentes do ensino superior, já habituados à pesquisa, cresceu o interesse pela temática da formação de professores para a educação básica e pela influência da política do Pibid. Essa constatação se torna visível quando se observa o crescente número de textos publicados nos últimos anos abordando o
Pibid como tema central ou como elemento de pesquisa em estudos sobre formação de professores e prática docente, como expressa o gráfico $2 .^{7}$

Gráfico 2. Textos sobre o Pibid

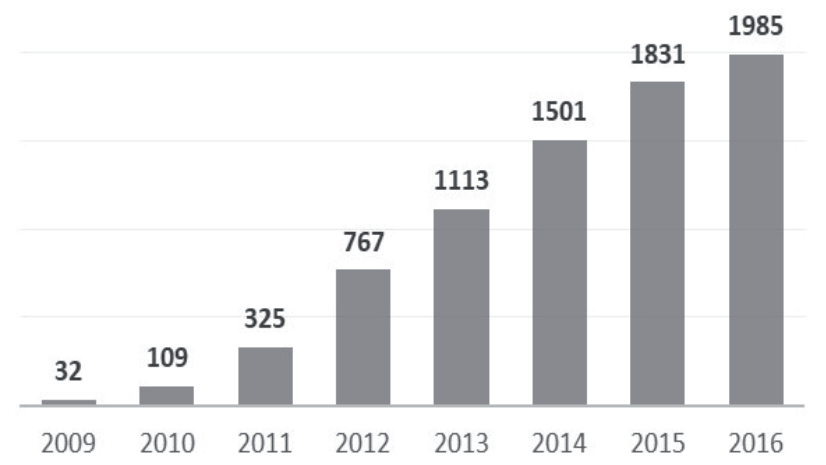

Fonte: Google Acadêmico, 2017. Elaboração dos autores.

A Capes, por meio da DEB e através do Pibid, empreendeu a valorização da licenciatura aos estudantes do ensino superior e estendeu a formação continuada aos professores de escolas públicas, respondendo à necessidade socialmente posta de pensar a profissionalização da docência, levando em conta os entraves da educação básica no país, os desafios da escola pública e o contexto socioeconômico das comunidades onde estão inseridas essa educação e essa escola. Isso tem formado profissionais conhecedores da realidade e também agentes capazes de intervir nessa mesma realidade como protagonistas, como veremos no próximo tópico, na análise das informações colhidas com os pesquisados.

\section{Agentes pedagógicos protagonistas}

Embora tenha sido um programa com um curto tempo de duração, e que ainda não foi suficientemente avaliado e tampouco tenha chegado a ser otimizado com correções para proporcionar efeitos ainda mais vultosos na educação básica e na formação docente, em dez anos de existência, e oito de implementação

${ }^{7}$ Número de textos publicados (artigos científicos, trabalhos apresentados em encontros acadêmicos e resumos em anais) que abordam o Pibid, direta ou indiretamente. 
das bolsas, o Pibid avançou além do seu planejamento inicial e se tornou um dos mais importantes programas voltados para a formação e atualização de professores. Enquanto proposta de valorização do magistério e aprimoramento do processo de formação de docentes para a educação básica, ele colocou na esfera direta de relacionamento professores e estudantes do ensino superior e da educação básica, incentivando esses educadores e educandos ao exercício coletivo das atividades pedagógicas desempenhadas em escolas públicas nos ensinos infantil, fundamental e médio.

$\mathrm{Na}$ demonstração de que essa aproximação se traduz em trabalho coletivo e formação conjunta, e com o entendimento de que as experiências vividas geram saberes que devem ser compartilhados, nessa parte do artigo trataremos de apresentar as principais mudanças produzidas pelo Pibid sobre os agentes diretamente relacionados, que modificam e ao mesmo tempo são modificados em sua formação e atuação profissional. Os agentes aqui considerados estão representados em quatro grupos distintos, que são os coordenadores (professores do ensino superior), os supervisores (professores da educação básica), os iniciantes à docência (estudantes do ensino superior) e os estudantes da educação básica.

\section{Os coordenadores}

Entre os professores do ensino superior que ocupam a função de coordenação institucional ou de área, foi relatada a importância do contato com as escolas para a consecução de suas atribuições acadêmicas. Como o Pibid tem promovido e fortalecido o diálogo entre esses e as unidades onde os bolsistas e supervisores atuam diretamente, o resultado desse diálogo presente é a ocorrência, entre os coordenadores, de gradativas revisões dos seus planos de ensino para as disciplinas ministradas. Também foram apontadas algumas mudanças na execução das aulas, com a adoção de novas linguagens e tecnologias da informação e da comunicação, sempre a partir de respostas ou sugestões trazidas pelos estudantes por meio de suas vivências nas escolas.

Ainda surge como produto dessa interação, a crescente produção e publicação de textos científicos e apresentações de trabalhos em eventos acadêmicos que abordam a temática da formação de professores. O conhecimento da realidade praticada no cotidiano da escola e o contexto social onde se aplica a teoria ou que se choca com ela, propiciaram aos docentes de diferentes disciplinas do ensino superior a vivência real e contextualizada da prática escolar, fato que anteriormente era de conhecimento especificamente dos professores de estágio supervisionado ou de disciplinas práticas, que obtinham informações por meio dos retornos trazidos por seus orientandos e estagiários, ou pelo uso da sala de aula da escola como laboratório.

Relatos descritos por Silva e Martins (2014) também identificam esse crescimento profissional dos professores universitários envolvidos no programa. Esses relatos indicam que os coordenadores institucionais e os coordenadores de subprojetos, da mesma forma que os professores das escolas participantes, crescem profissionalmente pelo aprendizado gerado e proporcionado no Pibid, fator que tem elevado a demanda nas instituições por esse programa, bem como vem promovendo maiores reflexões e importantes pesquisas acerca da formação de professores da educação básica entre os professores do ensino superior.

\section{Os supervisores}

Observa-se na história das políticas públicas educacionais, voltadas para a formação continuada de professores, a descontinuidade dos projetos e o descaso com que muitas vezes são tratadas essas políticas, desgastadas pela falta de investimentos e pela pouca prioridade atribuída à sua execução, principalmente quando se trata do aperfeiçoamento docente para a educação básica. Por outro lado, esses profissionais são sufocados com uma carga horária extensa que dificulta a qualificação por iniciativa própria. Pelo excessivo acúmulo de trabalho que comumente é atribuído ao professor da educação básica, quando se trata do estágio docente, esses tendem a recusar o acompanhamento de novos estagiários, como observa Jardilino (2014), justificando que estão sobrecarregados. Tornou-se comum ouvir, entre os supervisores, que geralmente não há tempo suficiente em sua carga horária de trabalho para se envolver com os estagiários. Assim, a prática do estágio na escola torna-se bastante limitada, sem o devido acompanhamento e 
a orientação do professor. Já no caso do Pibid, a bolsa repassada pela Capes torna-se um incentivo diferenciado, fazendo-o se envolver mais na orientação e supervisão das atividades desempenhadas pelos estudantes bolsistas, permitindo inclusive, em alguns casos, que o professor abra mão de alguma atividade remunerada para se dedicar ao Pibid, sendo compensado pela bolsa de supervisão.

Com isso, os professores da educação básica, que atuam como supervisores do programa, percebem nessa interação mais frequente com discentes e docentes da educação superior, uma motivação profissional e uma oportunidade de formação continuada. Para alguns supervisores, o contato com as instituições formadoras e a renovação das práticas pedagógica no cotidiano das escolas, propiciadas pelas intervenções pontuais dos estudantes de iniciação à docência, despertaram o interesse pela continuidade dos estudos com a realização de cursos de pós-graduação (lato sensu ou stricto sensu) e a atualização em cursos específicos promovidos pelas redes de ensino. Essa percepção da aprendizagem recíproca se assemelha ao atilamento de Ambrosetti et al (2013), que compreenderam, nesse processo de aproximação, que o professor supervisor, atuante na educação básica, em seu papel fundamental de coorientação no programa, de um lado, se realiza com a transmissão de orientações aos estudantes sobre a postura do professor e as práticas, rotinas e normas institucionais do ambiente escolar, e de outro, ele também se capacita ao receber do orientando o apoio para desenvolver suas atividades pedagógicas previstas e, ao mesmo tempo, proceder o desenvolvimento de novas técnicas e métodos de ensino e aprendizagem, com a colaboração imediata dos estudantes que na universidade têm acesso e conhecimento de novas tecnologias utilizadas na educação.

Essa reaprendizagem dos professores supervisores confirma o pensamento de Tardif (2000), para quem os conhecimentos profissionais, tanto em suas bases teóricas quanto em suas ações práticas, são evolutivos e progressivos, e por isso necessitam de uma formação continuada, ou seja, depois da formação universitária, os profissionais precisam se autoformar e se atualizar através de diferentes meios. Desse ponto de vista, o aperfeiçoamento pro- fissional deve ocupar um lugar primordial na formação docente. E essa passou a ser uma opção proporcionada pelo Pibid.

\section{Os iniciantes à docência}

A integração entre universidade e escola, entre teoria e prática, entre professores e estudantes de diferentes instituições de ensino, propicia o conhecimento da realidade escolar e a formação contextualizada, que por sua vez provocam a reflexão sobre a atuação profissional almejada e a descoberta do espaço limitado de autonomia que o professor tem em seu exercício profissional. Essas informações são relevantes aos graduandos participantes do Pibid (bolsistas e voluntários), que revelaram, ainda, a descoberta de uma percepção geral de que o programa possibilitou um reencontro com a escola. Ambrosetti et al (2013) descrevem esse momento como um instante de redescobertas. $\mathrm{O}$ ingresso do estudante na escola pública, ou o retorno, para os que estudaram nela, revela um universo desconhecido e cercado por preconceitos, com momentos de tensão e curiosidade, no reencontro desse espaço, agora com um olhar envolvido pelas teorias acadêmicas.

Esses estudantes estiveram lá quando crianças e adolescentes, quando frequentavam o ensino básico e enxergavam o ambiente escolar com outros olhos. Agora, de volta à escola e com um conhecimento modificado sobre a educação, promovido pela formação profissional, eles visualizam o mesmo espaço com outro olhar, concebendo-o como outro ambiente, diferente daquele que haviam frequentado antes. Embora o espaço tenha mudado pouco, o olhar foi bastante modificado, alterando também a percepção de mundo e a concepção das relações sociais que se dão na prática do ensino. Com esse mesmo entendimento, Gonçalves e Lima Filho (2014) afirmam que a aprendizagem ocorre pela ação de vivenciar a escola em seu cotidiano, estando presente em suas atividades corriqueiras, na observação das aulas, reuniões, planejamentos, intervalos, entrada e saída dos estudantes, compreendendo, assim, toda a dinâmica social própria da escola.

O conhecimento da profissão e do ambiente de trabalho ainda permite aos formandos uma identificação maior com o curso e a sua valorização. Muitos dos 
estudantes relataram a percepção dessa valorização dos cursos de licenciatura em toda a comunidade acadêmica. Os bolsistas também destacaram que, diferentemente do estágio, que tem um acompanhamento distanciado do orientador, pois esse opera na graduação e não acompanha a atuação do estagiário na escola, a não ser por meio de relatórios e fichas de acompanhamento, no Pibid, tanto as observações quanto as intervenções, contam com a supervisão imediata dos professores da unidade escolar.

Também foi destacada, entre os estudantes pibidianos, a realização de eventos interdisciplinares em cada instituição, bem como eventos entre Pibids de diferentes instituições, ações que criam oportunidades de promoção e troca de experiências e o aprimoramento das práticas de ensino com a adoção de atitudes criativas e inovadoras. E ainda, no relato de alguns dos estudantes que iniciaram o curso de licenciatura sem muito interesse, como uma opção de formação secundária, o Pibid serviu de experiência para a definição da profissão. Mesmo para aqueles que desistiram da docência, o programa teve um papel primordial em sua descoberta. O fato de estar inserido na escola e passar a experimentar a instituição em toda a sua complexidade, permite ao estudante de iniciação à docência um olhar mais realista do trabalho educacional, algo que o ajuda na decisão de seguir ou não na profissão. Decisão que pode ser tomada o quanto antes, para confirmação ou mudança de formação, se for o caso, e para que a descoberta não se revele apenas após a conclusão do curso e a entrada no mercado de trabalho.

Porém, cabe aqui o registro da preocupação dos bolsistas de iniciação à docência quanto ao futuro profissional, isso porque reconhecem no Pibid e nas políticas atualmente existentes, uma ação paliativa que se restringe à formação, mas não enxergam incentivos profissionais para o exercício da docência na educação básica. A falta de estrutura adequada de trabalho nas escolas, o excesso de aulas e os baixos salários são pontos que aparecem nas indagações dos estudantes quanto ao futuro na profissão.

\section{Os estudantes da educação básica}

Para discorrer esse tópico, foram pesquisados os estudantes de duas escolas atendidas por ações do Pibid, nas quais foram observados resultados que demonstram o quanto eles são beneficiados com a presença e atuação dos bolsistas nas atividades escolares, seja pelas intervenções pontuais nas aulas, pela integração nos eventos escolares (jogos, feiras, excursões, etc.), ou pela mobilização no uso de novas técnicas e tecnologias de comunicação. Por exemplo, os bolsistas mais jovens apresentam linguagens verbal e visual mais próximas às linguagens utilizadas pelos adolescentes do ensino médio e isso estabeleceu entre eles, estudantes do ensino médio e estudantes de licenciatura, uma comunicação bem mais prática e horizontal, o que proporcionou outra dinâmica às ações pedagógicas, como o emprego de novas músicas, filmes e textos mais voltados para os jovens e adolescentes e pouco conhecidos pelos professores de mais idade. A relação democrática e horizontal em sala de aula torna-se essencial para o estabelecimento de um diálogo voluntário e participativo nesse micro espaço público. ${ }^{8}$

De acordo com os estudantes da educação básica pesquisados nesse estudo, a utilização dos espaços da escola foi potencializada com a presença dos pibidianos. Mesmo em situações onde a infraestrutura não se apresentava na forma mais adequada às atividades propostas, registrou-se uma adaptação dos espaços para essas práticas pedagógicas, com a junção da motivação dos professores ao desejo de mudança trazido pelos estudantes do Pibid. Isso fez surgir ambientes diferenciados para recreação e atividades lúdicas, para aulas extras de apoio à resolução de provas do Exame Nacional do Ensino Médio (Enem), e também a dinamização dos eventos de leituras na biblioteca, da feira científica e cultural, dos experimentos em laboratórios de ciências e informática, etc. A valorização do espaço é condição favorável ao envolvimento da comunidade escolar, criando a identificação do estudante com o ambiente de ensino e ampliando a sua participação e, consequentemente, o seu desempenho.

\footnotetext{
${ }^{8} \mathrm{Ou}$ espaço micropúblico, no sentido arendtiano e habermasiano de esfera pública, correspondente ao espaço público urbano midiatizado, que compreende a esfera onde os debates ocorrem em pequenos grupos formados por pessoas próximas, consumidoras de informações da mídia e que se reúnem, não necessariamente para conversar sobre política, mas acabam tomando parte desse tema (CARMO, 2011).
} 


\section{Considerações finais}

Para concluir esse estudo, ressaltamos que dentre as ações proporcionadas pelo Pibid, destacase o desenvolvimento de novas concepções sobre a educação, sobre a escola pública e sobre as práticas educativas resultantes da aproximação entre universidades e escolas, entre os professores (coordenadores e supervisores), os licenciandos bolsistas e os estudantes das escolas. O múltiplo caráter formativo do programa orienta para a intervenção na escola e a construção de reflexões sobre essas práticas, habilitando os envolvidos para a construção de novos saberes e novas maneiras de ver e entender o espaço escolar, as práticas docentes, as formulações teóricas e as aplicações empíricas. Por isso, durante os seus dez anos de existência, o Pibid foi reconhecido como uma política pública de alto impacto sobre a formação de professores (GATTI et al, 2014), tendo suas ações o potencial de elevar a qualidade do trabalho docente e discente nas escolas e nas universidades.

Entretanto, por se tratar de um programa de grandiosa envergadura, com um volumoso montante de capital empenhado e um enorme quantitativo de pessoas envolvidas, entendemos que ainda se faz necessária a realização de uma avaliação mais abrangente dos efeitos do programa sobre a qualidade da formação dos egressos, como alerta André (2012), e sobre a posterior alocação desses egressos no campo de trabalho, ou mesmo sobre a relação desse programa com outros voltados à formação de professores. Também fica em evidência a necessidade de preservação e ampliação do programa de bolsas, face à enorme parcela de licenciandos não atendidos por essa política. E ainda, é preciso considerar que perdura um grave problema da educação básica que não recebeu a devida preocupação nas políticas públicas educacionais: a sobrecarga de trabalho do professor, que geralmente o deixa sem tempo suficiente em sua carga horária para se dedicar à orientação e supervisão, como se faz necessário.

Outro problema que persiste é o da elevada taxa de evasão nos cursos superiores. Nos cursos de formação de professores, o impacto é bem maior na descontinuidade dos estudos, seja por motivos pessoais ou conjunturais. Contudo, entre os participan- tes do Pibid, como descrevem Santos Junior e Real (2017), foi observado um entendimento geral de que o programa produziu a redução da evasão e a melhoria do desempenho acadêmico entre os pibidianos, o que, por sua vez, reduziu a retenção, que ainda assim continua sendo uma preocupação central aos cursos de graduação e em especial às licenciaturas. Por outro lado, fica claro que, ao estimular a aproximação entre universidade e escola e proporcionar condições favoráveis à inserção antecipada dos estudantes de cursos de formação de professores diretamente no ambiente escolar, o programa fortaleceu a identificação do estudante com o curso e com a profissão, ação que tende a reduzir a evasão e elevar o desempenho. Com isso, o Pibid cumpriu a sua função crucial de valorizar a formação docente e repensar a educação básica da rede pública de ensino, assumindo assim um potencial papel transformador das práticas de ensino acadêmicas e escolares, capaz de beneficiar ambas as instituições e criar possibilidades para a constituição de espaços privilegiados de trabalho e de formação.

Com o Pibid foi possível perceber que, a partir da inserção dos estudantes universitários no ambiente escolar, esses levam de volta para as salas de aula das universidades as questões vivenciadas no cotidiano do professor da educação básica. E esse fato, também observado e descrito por Ambrosetti et al (2013) e Gatti et al (2014), evidencia que o retorno desse saber adquirido em campo alimenta o entendimento coletivo sobre a dimensão do saber fazer e do saber ser, e difunde um novo olhar sobre os conhecimentos teóricos, agora submetidos à releitura pelo filtro da prática. A partir dessa retroalimentação das práticas nos cursos de formação de professores, com base na realidade observada e vivenciada pelos participantes do programa, surgem novos profissionais, em todas as áreas de ensino, com experiências concretas que permitem o conhecimento da realidade do ensino público no país e a ação coletiva e planejada sobre ela, fazendo desses agentes pedagógicos os verdadeiros protagonistas da sua própria formação docente, agentes transformados e transformadores nessa rica experiência de ensino.

Sobre o Programa de Residência Pedagógica, essa é uma política a ser detalhadamente pesquisada em outros estudos e a partir do momento em que esse novo programa esteja em pleno processo pós-im- 
plementação, possibilitando os estudos comparados. Por enquanto, as propostas apresentadas não acrescentam ao programa anterior, ao contrário, reduz as possibilidades já implantadas pelo primeiro programa, pois limita a participação dos alunos, que precisam ter cursado, no mínimo, o $5^{\circ}$ período do curso, e ainda impõe o entrave burocrático, pois antes era possível a relação direta entre a instituição de ensino superior e a instituição de educação básica. Com o novo programa, há a necessidade de um Acordo de Cooperação Técnica firmado entre a Capes e as secretarias de educação dos estados e municípios. Com isso, a Capes e as secretarias de educação aparecem no programa como duas agências intermediárias na relação entre universidade e escola.

\section{REFERÊNCIAS}

AMBROSETTI, N. et al. Contribuições do Pibid para a formação inicial de professores: o olhar dos estudantes. Educação em Perspectiva, v. 4, n. 1, p. 151-174, jan./ jun. 2013. Disponível em: < http://www.seer.ufv.br/seer/ educacaoemperspectiva/index.php/ppgeufv/article/ view/405/0 >. Acesso em: 22 ago. 2017.

AMORIM, D.; VIEIRA J. Enfoques epistemológicos do programa institucional de bolsa de iniciação à docência / Pibid na formação docente. Revista Semiárido De Visu, v. 4, n. 3, p. 132-145, 2016. Disponível em: < file:///C:/Users/Giovana/Downloads/258-1696-1-PB. pdf >. Acesso em: 15 ago. 2017.

ANDRÉ, M. Políticas e programas de apoio aos professores iniciantes no Brasil. Cadernos de Pesquisa, v. 42, n. 145, p. 112-129, jan./abr. 2012. Disponível em: $<$ http://www.scielo.br/scielo.php?script=sci arttext\&pi$\mathrm{d}=\mathrm{S} 0100-15742012000100008 \&$ lang $=\mathrm{pt} \quad>$. Acesso em: 16 ago. 2017.

BRASIL. Lei 13005/14. Plano Nacional de Educação. Disponível em: < http://www.planalto.gov.br/CClVIL 03/ Ato2011-2014/2014/Lei/L13005.htm >. Acesso em: 12 ago. 2017.

CAPES. Diretoria de Formação de Professores da Educação Básica - DEB. Relatório de Gestão PIBID. Brasília, 2013. Disponível em: < https://www.capes. gov.br/images/stories/download/bolsas/1892014-relatorio-PIBID.pdf >. Acesso em: 10 set. 2017.
CARMO, E. O espaço micropúblico. Recife: Universitária. 2011. Disponível em: < http://www.dominiopublico.gov.br/pesquisa/DetalheObraForm.do?select action=\&co_obra=204481 >. Acesso em: 26 set. 2017. CARMO, E. et al. Políticas públicas de democratização do acesso ao ensino superior e estrutura básica de formação no ensino médio regular. Revista Brasileira de Estudos Pedagógicos, v. 95, n. 240, p. 304-327, mai./ago. 2014. Disponível em: < file:///C:/Users/Giovana/Downloads/309-341-1-PB.pdf $>$. Acesso em: 12 out. 2017.

GATTI, B. et al. Um estudo avaliativo do Programa Institucional de Bolsa de Iniciação à Docência. São Paulo: Fundação Carlos Chagas, 2014. Disponível em: < https://www.capes.gov.br/images/stories/download/ bolsas/24112014-pibid-arquivoAnexado.pdf >. Acesso em: 05 set. 2017.

CHENG, M. et al. Pre-service teacher education students apistemological beliefs and their conceptions of teaching. Teaching and Teacher Education, v. 25, n. 2, p. 319-327, 2009. Disponível em: < http://www.sciencedirect.com/science/article/pii/S0742051X08001728 >. Acesso em: 09 set. 2017

GONÇALVES, D.; LIMA FILHO, I. Aprendendo pela pesquisa e pelo ensino: o Pibid no processo formativo das licenciaturas em Ciências Sociais. Revista Brasileira de Sociologia, v. 2, n. 3, p. 79-100, jan./jun. 2014. Disponível em: < http://www.sbsociologia.com. br/revista/index.php/RBS/article/view/62 >. Acesso em: 20 ago. 2017.

JARDILINO J. Políticas de formação de professores em conflito com o currículo: estágio supervisionado e Pibid. Educação, v. 39, n. 2, p. 353-366, mai./ago. 2014. Disponível em: < https://periodicos.ufsm.br/reveducacao/article/view/12068 >. Acesso em: 15 ago. 2017.

SKAMP, K.; MUELLER, A. A longitudinal study of the influences of primary and secondary school, university and practicum on student teachers images of effective primary science practice. International Journal of Science Education, v. 23, p. 227-245, 2001. Disponivel em < http://www.tandfonline.com/doi/ abs/10.1080/095006901750066493 >. Acesso em: 09 set. 2017 . 
NASCIMENTO, M.; ALMEIDA, P.; PASSOS, L. Formação docente e sua relação com a escola. Revista Portuguesa de Educação, v. 29, n.2, p. 0934, 2016. Disponível em: < http://www.redalyc.org/ html/374/37449632002/ >. Acesso em: 11 jul. 2017.

OLIVA, A.; MARTÍNEZ, A.; POZO, R. Tendências metodológicas em los docentes universitarios que forman al profesorado de primaria y secundaria. Revista Brasileira de Educação, v. 21, n. 65, p. 391-409, abr./jun. 2016. Disponível em: < http://www.scielo.br/pdf/rbedu/ v21n65/1413-2478-rbedu-21-65-0391.pdf >. Acesso em: 09 set. 2017.

PAULILO, A. Um capítulo da história da formação e da profissão docente no Brasil: o Instituto de Educação do Distrito Federal e sua historiografia. Educação \& Sociedade, v. 38, n. 138, p 117-132, jan./mar. 2017. Disponível em: < http://www.scielo.br/pdf/es/ v38n138/1678-4626-es-ES0101_73302016139962. pdf >. Acesso em: 04 set. 2017.

SANTOS JUNIOR, J.; REAL, G. A evasão na educação superior: o estado da arte das pesquisas no Brasil a partir de 1990. Avaliação, v. 22, n. 2, jul./nov. 2017. Disponível em: < http://www.scielo.br/scielo.php?pi$\mathrm{d}=\mathrm{S} 1414-40772017000200385 \& \mathrm{script}=\mathrm{sci}$ arttext\&tln$\mathrm{g}=\mathrm{pt}$ >. Acesso em: 23 ago. 2017.

SAVIANI, D. Formação de professores: aspectos históricos e teóricos do problema no contexto brasileiro. Revista Brasileira de Educação, v. 14, n. 40, p. 143-155, jan./abr. 2009. Disponível em: < http://www. scielo.br/pdf/rbedu/v14n40/v14n40a12 >. Acesso em: 02 set. 2017.
SAVIANI, D.; DUARTE, N. A formação humana na perspectiva histórico-ontológica. Revista Brasileira de Educação, v. 15 , n. 45, p. 422-590, set./dez. 2010. Disponível em: < http://www.scielo.br/pdf/rbedu/ v15n45/02 >. Acesso em: 03 set. 2017.

SILVA, M.; MARTINS, A. Reflexões do Pibid-Química da UFRN: para além da iniciação à docência. Química Nova Escola, v. 36, n. 2, p. 101-107, mai. 2014. Disponível em: < http://qnesc.sbq.org.br/online/qnesc36_2/ 05-EA-97-12.pdf >. Acesso em: 08 jul. 2017.

SILVA, W. Formação sustentável do professor no mestrado profissional. Revista Brasileira de Educação, v. 22 , n. 70 , p. $708-731$, jul. 2017. Disponível em: < http://www.scielo.br/scielo.php?script=sci_arttext\&pi$\mathrm{d}=\mathrm{S} 1413-24782017000300708 \& \mathrm{lng}=\mathrm{pt} \& \mathrm{nrm}=\mathrm{iso} \quad>$. Acesso em: 17 set. 2017.

TARDIF, M. Saberes profissionais dos professores e conhecimentos universitários. Revista Brasileira de Educação, n. 13, p. 5-24, abr. 2000. Disponível em: < http://teleduc.unisa.br/ teleduc/cursos/diretorio/ apoio 5427 368/TARDIF Saberes profissionais dos professores.pdf $>$. Acesso em: 15 out. 2017. VASCONCELOS, C.; OLIVEIRA, E. TIC no ensino e na formação de professores: reflexões a partir da prática docente. Revista Brasileira de Ensino Superior, v. 3, n. 1, p. 112-132, ago. 2017. Disponível em: < https:// seer.imed.edu.br/index.php/REBES/article/view/1592 >. Acesso em: 07 nov. 2017.

(Footnotes)

$1 \quad$ Nas diferentes habilitações (Biologia, Química, Física e Ciências Naturais). 